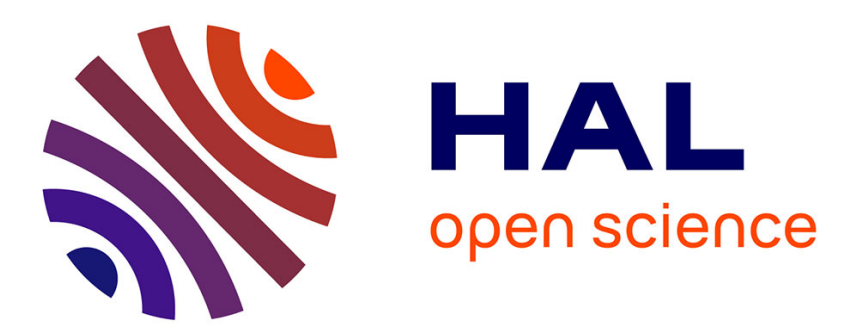

\title{
Design of a directive and matched antenna with a planar EBG structure
}

\author{
Halim Boutayeb, Kouroch Mahdjoubi, Anne-Claude Tarot
}

\section{To cite this version:}

Halim Boutayeb, Kouroch Mahdjoubi, Anne-Claude Tarot. Design of a directive and matched antenna with a planar EBG structure. Sep 2004, pp. 835-838, 10.1109/APS.2004.1329800 . hal-00133740

\author{
HAL Id: hal-00133740 \\ https://hal.science/hal-00133740
}

Submitted on 27 Feb 2007

HAL is a multi-disciplinary open access archive for the deposit and dissemination of scientific research documents, whether they are published or not. The documents may come from teaching and research institutions in France or abroad, or from public or private research centers.
L'archive ouverte pluridisciplinaire HAL, est destinée au dépôt et à la diffusion de documents scientifiques de niveau recherche, publiés ou non, émanant des établissements d'enseignement et de recherche français ou étrangers, des laboratoires publics ou privés. 


\title{
DESIGN OF A DIRECTIVE AND MATCHED ANTENNA WITH A PLANAR EBG STRUCTURE
}

\author{
H. BOUTAYEB ${ }^{1}$, K. MAHDJOUBI ${ }^{2}$ and A.C. TAROT ${ }^{2}$ \\ ${ }^{1}$ INRS Telecommunications, Montreal - Canada \\ ${ }^{2}$ IETR, University of Rennes 1, Rennes - France \\ Halim.Boutayeb@univ-rennes1.fr
}

\begin{abstract}
The purpose of this presentation is to propose a method to design a directive and matched antenna with a planar Electromagnetic Band Gap (EBG) structure. The EBG structure of our example consist on metallic wires. This study use the FDTD method and analytical formulas.
\end{abstract}

\section{I - Introduction}

Several recent works concern periodic structures associated with microwave antennas to enhance there directivity [1][2][3][4]. However, to our knowledge, the impedance aspect is not enough studied. The objective of this presentation is to propose a method to match an antenna put inside a planar EBG structure. Before inserting a real antenna inside the EBG structure, we present a study of the angular filtering characteristics of the EBG structure and the input impedance with an excitation by a line source.

\section{II - Plane waves and infinite long metallic wires : angular filtering}

We first interest on the angular filtering aspect due to the EBG structure composed of two layers of metallic wires on each side of the excitation (Figure 1). Let us call $\mathrm{T}_{2 *_{2}}$ the transmission coefficient obtained with an excitation by plane waves (Figure 1). $\mathrm{T}_{2 * 2}$ is function of the frequency ' $\mathrm{f}$ ' and the angular incidence ' $\theta$ '. We obtain this coefficient $\left(T_{2 * 2}\right)$ using $(r, t)$, the complex reflection and transmission coefficients of one surface of metallic wires. To simplify the study we don't consider the angular dependency of $(r, t)$. $(r, t)$ are calculated by the FDTD method.

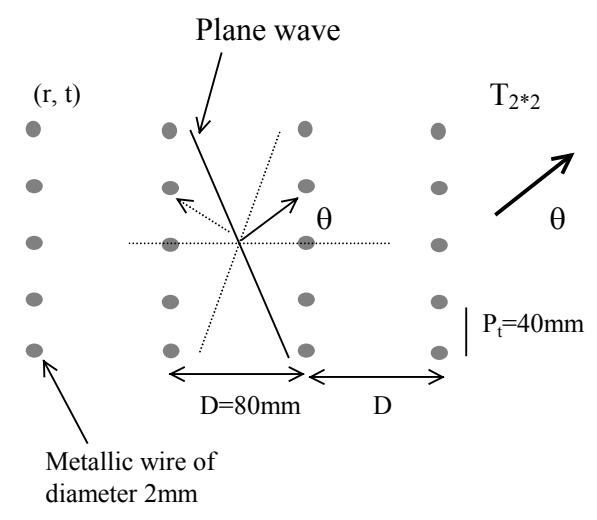

Figure 1-Transmission coefficient of the structure excited by plane waves.

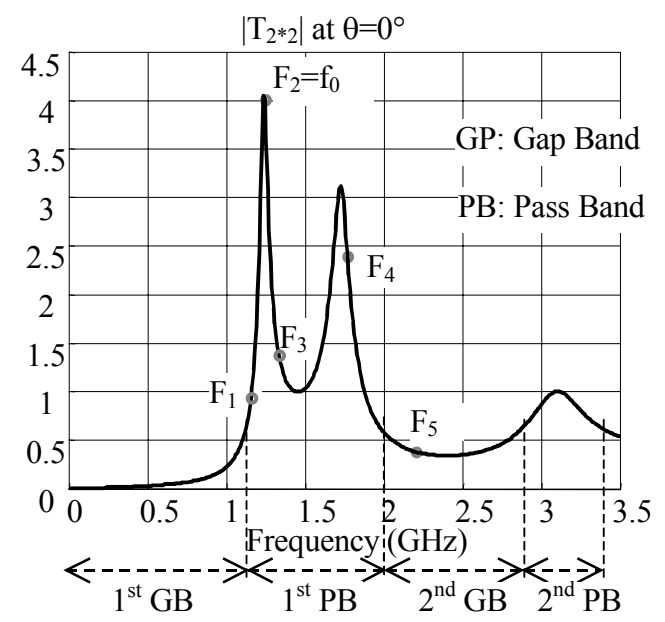

Figure $2-\left|T_{2 *_{2}}\right|$ versus frequency at normal incidence $\left(\theta=0^{\circ}\right)$.

The coefficient $\mathrm{T}_{2 * 2}(\mathrm{kD})$ can be written in a simple closed form [4][5] : 


$$
\mathrm{T}_{2 * 2}\left(\mathrm{kD}^{\prime}\right)=\frac{\mathrm{t}_{2}\left(\mathrm{kD}^{\prime}\right) \exp \left(-\mathrm{jkD}^{\prime} / 2\right)}{1-\mathrm{r}_{2}\left(\mathrm{kD}^{\prime}\right) \exp \left(-\mathrm{jk} \mathrm{D}^{\prime}\right)}
$$

with

$$
\mathrm{t}_{2}\left(k D^{\prime}\right)=\frac{\mathrm{t}(\mathrm{k})^{2} \exp \left(-\mathrm{jk} \mathrm{D}^{\prime}\right)}{1-\mathrm{r}(\mathrm{k})^{2} \exp \left(-\mathrm{jk} 2 \mathrm{D}^{\prime}\right)}, \mathrm{r}_{2}\left(k \mathrm{D}^{\prime}\right)=\mathrm{r}(\mathrm{k})\left(1+\frac{\mathrm{t}(\mathrm{k})^{2} \exp \left(-\mathrm{jk} 2 \mathrm{D}^{\prime}\right)}{1-\mathrm{r}(\mathrm{k})^{2} \exp \left(-\mathrm{jk} 2 \mathrm{D}^{\prime}\right)}\right)
$$

$\mathrm{k}$ is the free space wave number and $\mathrm{D}^{\prime}=\mathrm{D} \cos (\theta)$.

Figure 2 gives the transmission coefficient $\left|\mathrm{T}_{2 * 2}\right|$ versus the frequency at the normal incidence $\left(\theta=0^{\circ}\right)$. In this figure, is also represented the Gap Bands and the Pass Bands. We call $f_{0}$ the frequency corresponding to the first resonance. Figure 3 gives $\left|\mathrm{T}_{2 * 2}\right|$ versus the incidence angle at the different frequencies represented in Figure 2. These curves can be assimilated as radiation patterns. Until the first resonance $f_{0}$, the patterns have only one lobe at the normal, which is an objective for a directive antenna. At a frequency higher than $f_{0}$ the patterns have multiple lobes one each sides of the normal. Figure 3 gives a cartography form of $\left|T_{2 * 2}\right|$ versus ' $f$ ' and ' $\theta$ '.

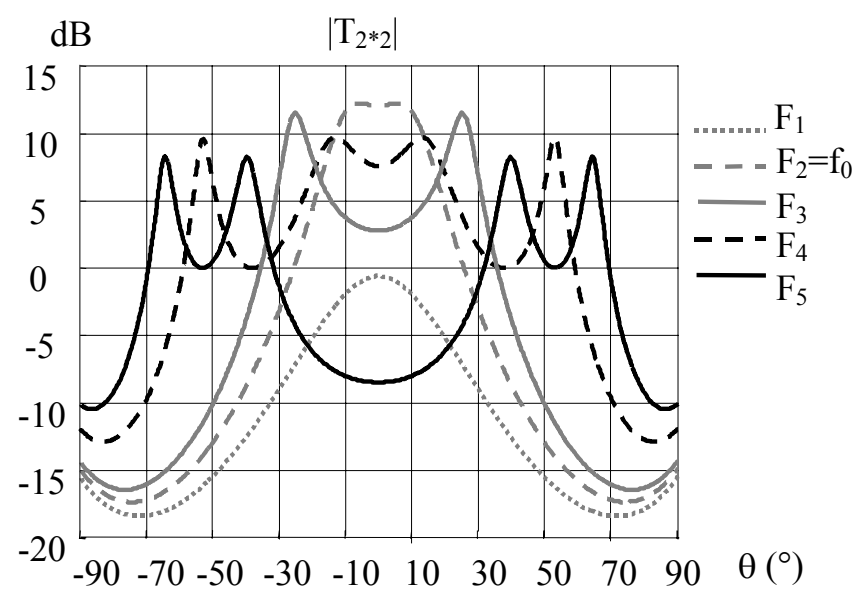

Figure $3-\left|T_{2 *_{2}}(\theta)\right|$ at the different frequencies represented in Figure 2.

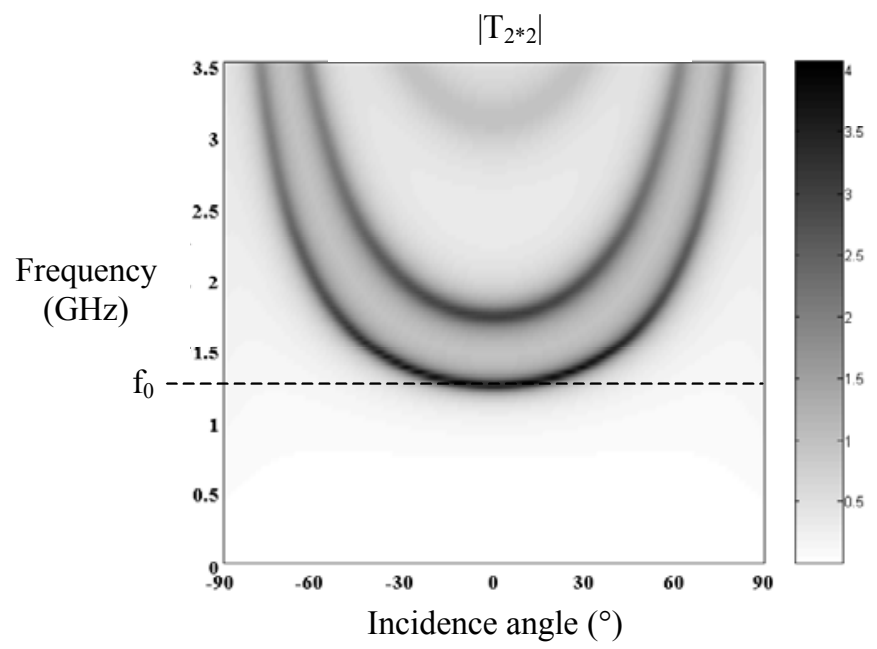

Figure-4 $-\left|T_{2 * 2}\right|$ versus incidence angle and frequency.

More details on the study of angular filtering and directivity of the structure can be found in ref. [5], and will be presented during the presentation. 


\section{III - Line source and infinite long metallic wires : input impedance}

In this paragraph, we consider infinite long metallic wires and an infinite long line source as the excitation (Figure 5a). In Figure 5b, we give the input impedance $Z_{I}$ for the source with and without the EBG structure. The input impedance is calculated by the FDTD method.

In the first Gap Band, the EBG structure gives a low real part which make difficult the matching of an antenna in this band. The matching is possible for frequencies higher than $\mathrm{f}_{0}$.

In the first Pass Band, the EBG structure add an imaginary part in the input impedance : as a result, the real source must be capacitive in this zone if we want to obtain a matched antenna.
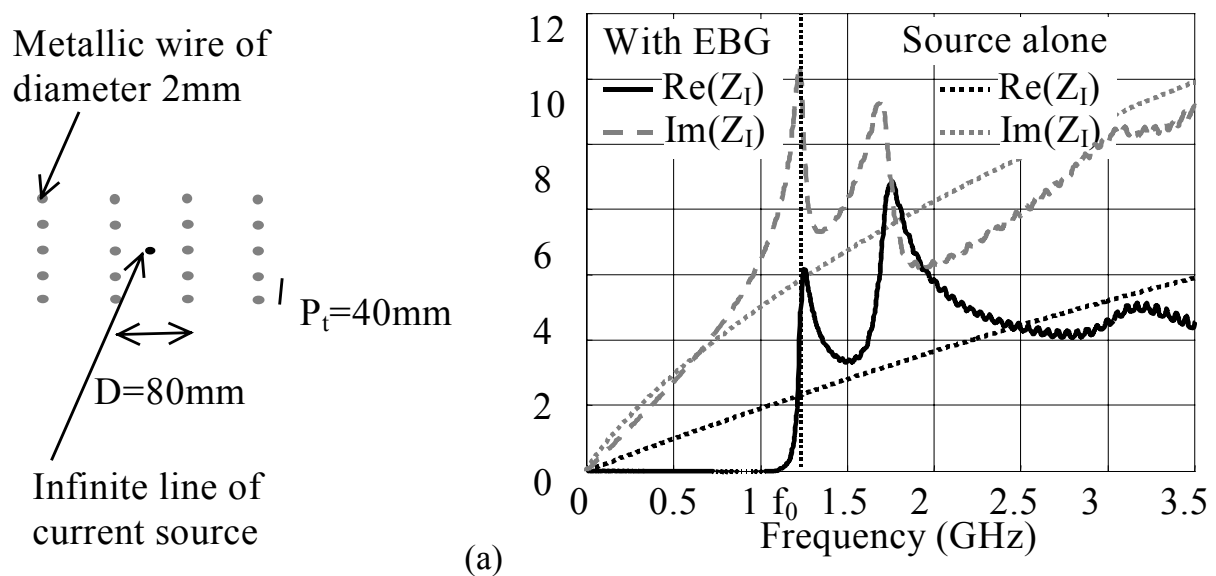

(b)

Figure 5 - (a) 2 layers of metallic wires on each side of an infinite line source (b) Input impedances $Z_{I}$ for the source with and without the EBG (FDTD).

\section{IV - Monopole and finite long metallic wires}

Let us now consider finite long metallic wires and a monopole as the exciting source (Figure 6). The frequency resonance of the monopole is called $f_{M}$. The matching curves for the monopole alone and for the complete structure is given for a monopole resonating before $f_{0}$ (Figure $7 \mathrm{a}$ ) and for a monopole resonating after $\mathrm{f}_{0}$ (Figure $7 \mathrm{~b}$ ). We know from paragraph II that if we want to obtain a directive antenna at the normal we should not go far away from $\mathrm{f}_{0}$. The matching of the complete structure is obtained in the second case only : the matched band $\left(6.7 \%\right.$ for $\left.\mathrm{S}_{11}<-10 \mathrm{~dB}\right)$ (Figure $\left.7 \mathrm{~b}\right)$ is between $f_{M}$ and $f_{0}$, which correspond to the intersection between the possible matching zone and the capacitive zone of the monopole $\left(\mathrm{f}<\mathrm{f}_{\mathrm{M}}\right)$.

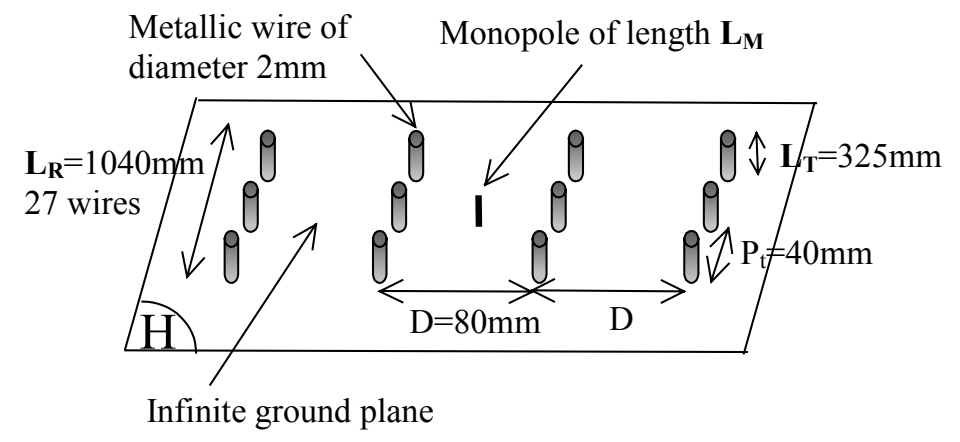

Figure 6-Monopole inside the finite EBG structure 
Figure 8 shows the radiation pattern of the structure in the H-plane (Figure 6 ) in the matched band (Figure 7b).

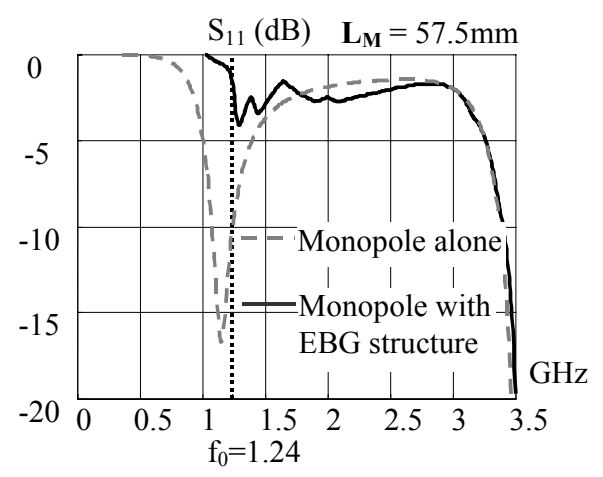

(a)

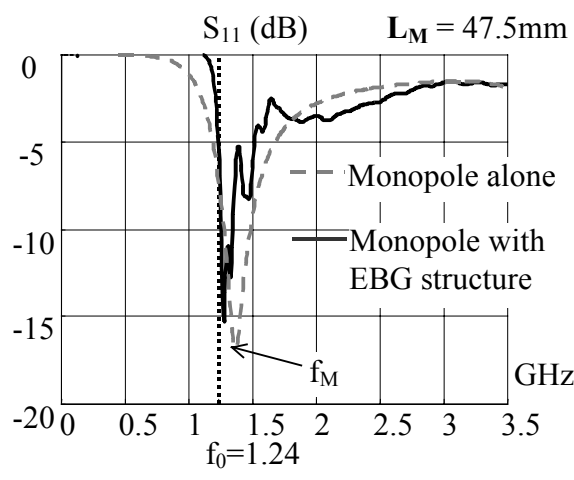

(b)

Figure 7 - Matching (a) Monopole resonating before $f_{0}$ (b) Monopole resonating after $f_{0}$

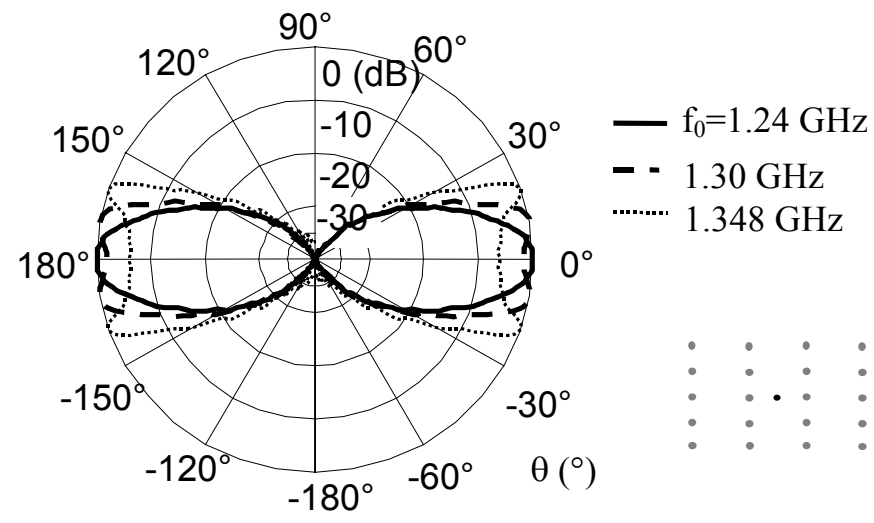

Figure 8-Radiation patterns in the H-plane, in the matched band (Figure 7b)(FDTD).

\section{V-Conclusion}

We have presented a method to design a directive and matched antenna using a monopole as the exciting source. The method consist on using a monopole which resonates at a frequency slightly higher than the first resonance of the transmission coefficient of the structure (which is calculated analytically).

In a future paper we will interest on structures composed of a patch antenna as the exciting source.

\section{References}

[1] M. THEVENOT, C. CHEYPRE, A. REINEX and B. JECKO, "Directive Photonic Band-Gap Antennas", IEEE Trans. On Microwave Theory and Techniques, vol. 47, no. 11, November 1999.

[2] R. BISWAS, E. OZBAY, B. TEMELKURAN, M. BAYDINDIR, M. SIGALAS et K.M. HO, "Exceptionally directional sources with Photonic Band-Gap crystals", Optical Society of America, v. 18, n. 11, November 2001.

[3] S. ENOCH, G. TAYEB, P. SABOUROUX, N. GUERIN and P. VINCENT, “ $A$ Metamatarial for Directive Emission", Phys. Rev. Lett., volume 89, No. 21, November 2002.

[4] H. BOUTAYEB, K. MAHDJOUBI and A.C TAROT, "EBG Antenna analysis/Unification of frequency and angular dependencies", ESA 2004.

[5] H. BOUTAYEB, "Etude des structures périodiques planaires et conformes associées aux antennes. Application aux communications mobiles", Thèse de l'Université de Rennes I, UFR Structures et Propriétés de la Matière, PhD Thesis, December 2003. 